\title{
LA CITA DE HERMARCO Y DE ALEXINO EN FILODEMO, RHET. II (PHERC. 1674), COL. XLIV 19 - XLIX 27
}

\author{
ANTONIO LUIS CHÁVEZ REINO
}

\begin{abstract}
Análisis de las razones por las que Filodemo cita al epicúreo Hermarco y al megárico Alexino de

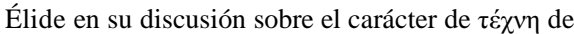
la retórica. Se corrigen algunas interpretaciones

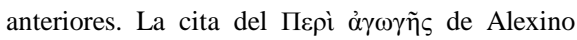
ilustra asimismo el sentido del testimonio $31 \mathrm{del}$ historiador Éforo de Cime (FGrHist 70 T 31).
\end{abstract}

Palabras-clave: Filodemo de Gádara; Hermarco; Alexino de Élide; Éforo de Cime; retórica; $\tau \varepsilon ́ \chi v \eta$.

\begin{abstract}
This paper deals with Philodemus' reasons for quoting Hermarchus the Epicurean and Alexinus the Megarian on the technicity of rhetoric. It purports to correct some former interpretations. The

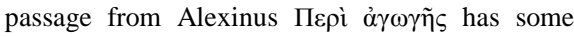
bearing, as well, on the elucidation of Ephorus' testimonium 31 (FGrHist 70 T 31).
\end{abstract}

Keywords: Philodemus of Gadara; Hermarchus the Epicurean; Alexinus of Elis; Ephorus of Cyme; rhetoric; $\tau \varepsilon ́ \chi v \eta$.

\section{Introducción}

En el testimonio 31 del historiador Éforo de Cime (FGrHist 70 T $31=$ Diógenes Laercio II 110) se dice escuetamente que el filósofo megárico Alexino de Élide «escribió también contra el historiador Éforo». Sobre el contenido de esta diatriba sólo existen dos hipótesis. La primera, debida a E. Schwartz y retomada por F. Jacoby, postula una crítica de carácter ético:

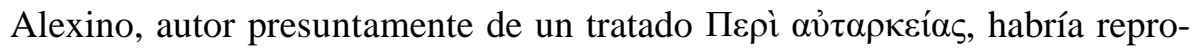

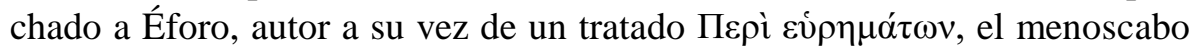

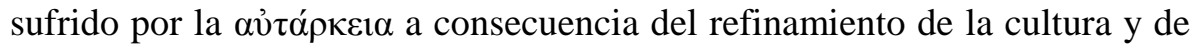
los progresos de la técnica ${ }^{1}$. La segunda hipótesis, debida a P. Pédech, sitúa la polémica en un ámbito político-erudito: Alexino habría criticado las tesis

1 E. Schwartz, art. Ephoros (1), RE VI/1 (1907), col. 3 (= Griechische Geschichtschreiber, Leipzig, 1959², pp. 6-7); F. Jacoby en FGrHist IIC, Berlín, 1926, p. 39. 
de Éforo sobre los orígenes de Élide, su patria ${ }^{2}$. Ninguna de estas dos hipótesis tiene un fundamento sólido.

Sí existe, en cambio, una clara relación entre la polémica de la que nos informa Diógenes Laercio y la crítica a la que Alexino somete, en un pasaje

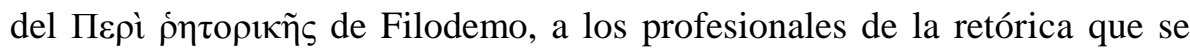

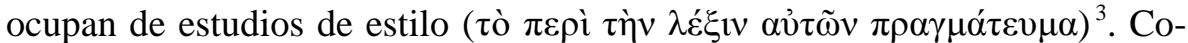

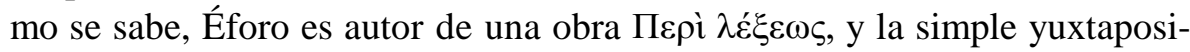
ción de este hecho y de la noticia de Filodemo permite constatar la existencia de un "punto de fricción" entre Alexino y Éforo capaz de dar contenido a la diatriba de la que nos informa Diógenes Laercio. Es un punto de partida sólido del que las otras hipótesis carecen.

El interés por los fragmentos de Éforo, en los que trabaja desde hace algunos años, ha traído al autor de estas páginas a ocuparse de la crítica de Alexino y a estudiar la posible conexión de esta crítica con el contenido del fragmento de Alexino transmitido por Filodemo ${ }^{4}$. Durante el estudio de este fragmento el autor ha podido percatarse de que en el texto de Filodemo existen ciertos puntos oscuros de estructura y de interpretación, y considera que es posible aportar en esta materia un poco de claridad. Estas páginas han sido escritas con ese sencillo propósito.

\section{El pasaje de Filodemo en su contexto}

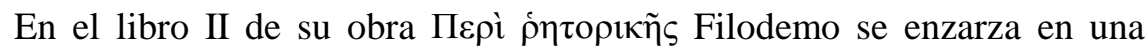
abierta polémica con ciertos epicúreos de Rodas y Cos acerca de la condi-

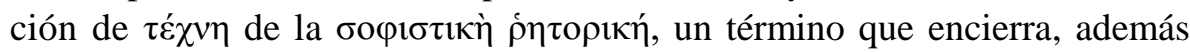
del significado concreto de 'oratoria epidíctica' que se le suele dar (por oposición a la deliberativa y la forense), el más amplio de 'teoría y práctica metódicas del discurso' ${ }^{5}$. Filodemo defiende en esta materia la postura sostenida por su maestro Zenón de Sidón, postura que considera la ortodoxa frente a la heterodoxia de los epicúreos de Rodas y Cos. La ortodoxia con-

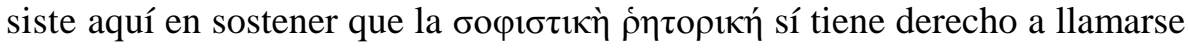

2 P. Pédech, La méthode historique de Polybe, París, 1964, p. 49 n. 120.

Filodemo, Rhet. II (PHerc. 1674), col. XLIV 28-30.

4 Las objeciones a las hipótesis de Schwartz y Pédech, así como la argumentación para probar que la crítica de Alexino a Éforo atestiguada por Diógenes Laercio se relaciona con el fragmento de Alexino transmitido por Filodemo, se publicarán en breve en otro lugar.

5 Véase más abajo, p. 262 y nota final, p. 265. 
$\tau \varepsilon ́ \chi v \eta$ y que así se deduce de los escritos de los próceres de la escuela (oi $\kappa \alpha \theta \eta \gamma \varepsilon \mu o ́ v \varepsilon \varsigma)$. Los epicúreos de Rodas y Cos lo negaban ${ }^{6}$.

La postura defendida por Filodemo se introduce en la columna XXXVII 1 como una nueva sección del libro. El propio autor indica allí, antes de entrar en materia, cuáles van a ser los pasos de su exposición: 1) qué se entiende

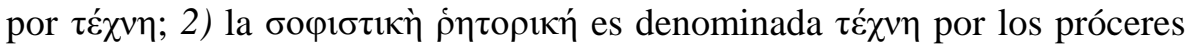

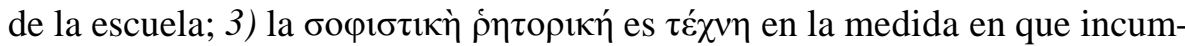
be a la elaboración del discurso y a la práctica epidíctica, pero no lo es en lo que se refiere a la práctica forense y deliberativa; y 4) la política no conlleva

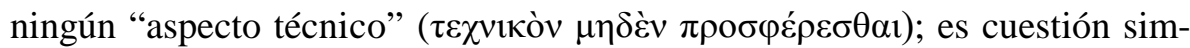
plemente de avezamiento y de conocimiento de los antecedentes históricos.

El segundo de estos puntos programáticos se desarrolla sobre todo en las columnas XLIII 26 a LII 3 y contiene citas de Epicuro (XLIV 2 - XLIV 9), Hermarco (XLIV 19 - XLIX 19) y Metrodoro (XLIX 27 - LI 29) ya aducidas

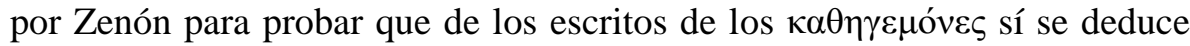

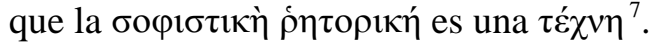

En el caso de Hermarco, la cita se toma de una carta dirigida a un tal Teofides en tiempos del arconte Menecles (267/6 a.C. $)^{8}$. En ella Hermarco combate una serie de argumentos u opiniones sostenidos por el megárico

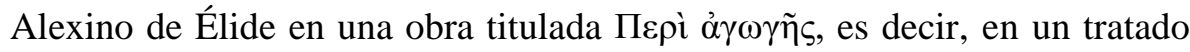
Sobre la Instrucción ${ }^{9}$. De la argumentación de Hermarco extrae Filodemo

6 Se hallará una útil introducción a la polémica de los epicúreos del s. I a.C. en torno a la condición de la retórica en D. Sedley, «Philosophical Allegiance in the Greco-Roman World», en M. Griffin - J. Barnes (eds.), Philosophia Togata. Essays on Philosophy and Roman Society, Oxford, 1989, pp. 107-117. Para los conceptos de ortodoxia y heterodoxia ligados a esta cuestión véase F. Longo Auricchio - A. Tepedino Guerra, «Aspetti e problemi della dissidenza epicurea», Cronache Ercolanesi 11, 1981, pp. 25-40. Para el lugar que la polémica

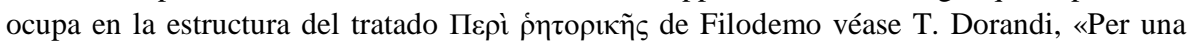
ricomposizione dello scritto di Filodemo sulla Retorica», ZPE 82, 1990, pp. 68-74, y la aún útil introducción de S. Sudhaus al primer volumen de su edición del tratado (Leipzig, 1892).

7 La discusión del punto prosigue hasta la columna XXII del PHerc. 1672. Filodemo se adentra en una profusa diatriba dirigida contra el anónimo epicúreo de Rodas (v. nota final)

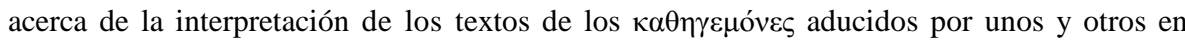
prueba de sus postulados.

8 J. Kirchner, Prosopographia Attica II, Berlín, 1903, p. 70, nº 9912, dató conjeturalmente el arcontado de Menecles en el año 283/2 a.C. T. Dorandi, «Testimonianze sugli arconti nei papiri ercolanesi», Cronache Ercolanesi 10, 1980, pp. 160-161, ha rebajado esa fecha a 267/6 a.C.

9 En un primer momento Teodoro Gomperz, que trabajaba con los apógrafos oxoniense 
los puntos que respaldan su tesis, según la cual también Hermarco entiende

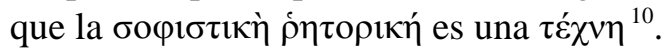

\section{El estado del texto}

El fragmento de Hermarco, que contiene el de Alexino, entraña ya de por sí la dificultad lógica de un pasaje en que un autor cita a otro autor que a su vez combate las opiniones de un tercero. En este caso la dificultad se agrava

y napolitano del PHerc. 1674, reconstruyó el nombre del autor contra el que polemizaba Her-

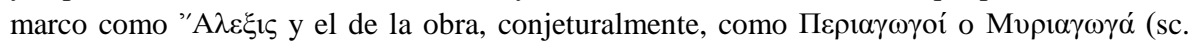

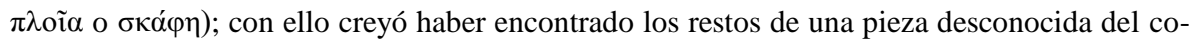
mediógrafo de Turios: véase Th. Gomperz, «Die herculanischen Rollen. Herculanensium voluminum Collectio altera. Tom. II, III, IV, V, 1. (Neapel 1862-1865.) II», Zeitschrift für die Österreichischen Gymnasien 16, 1865, p. 826, ahora en Theodor Gomperz. Eine Auswahl herkulanischer kleiner Schriften (1864-1909), hrsg. von T. Dorandi (Philosophia Antiqua, LIX), Leiden, 1993, p. 24. Th. Kock dio cabida al pasaje entre los textos de Alexis, no sin ciertas dudas que le inspiraban unos comentarios de A. Nauck: v. Th. Kock, Comicorum Atticorum fragmenta III, Leipzig, 1888, p. 744 (allí mismo las referencias a Nauck). También S. Sudhaus aceptó en un primer momento las conjeturas de Gomperz en el primer volumen de su

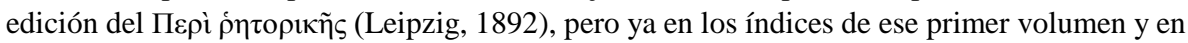
una nota publicada en 1893 tuvo ocasión de rectificar dando las lecturas correctas del papiro: v. S. Sudhaus, «Alexinos», RhM 48, 1893, pp. 152-154. El mismo año 1893, y de manera independiente, H. von Arnim propuso una lúcida reconstrucción de todo el pasaje restituyendo

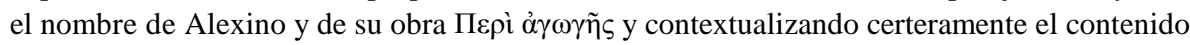
en el marco de la figura del filósofo megárico y de la naturaleza de los argumentos que Hermarco le criticaba: v. H. von Arnim, «Ein Bruchstück des Alexinos», Hermes 28, 1893, pp. 65-72. Sudhaus aceptó las principales propuestas de von Arnim en la versión mejorada del

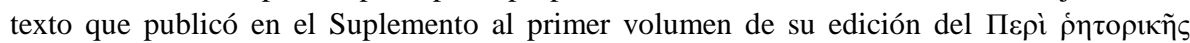
(Leipzig, 1895). Posteriormente, K. Döring, Die Megariker. Kommentierte Sammlung der Testimonien (Studien zur antiken Philosophie, 2), Amsterdam, 1972, pp. 25-26 (texto) y 117120 (traducción y comentario), editó la parte de la cita de Hermarco referida a Alexino como fr. 88 de su recopilación de testimonios sobre los megáricos. G. Giannantoni, Socraticorum reliquiae I (Elenchos, 7/1), Nápoles, 1983, pp. 65-66, editó asimismo el pasaje como fr. n 12 de Alexino (= Socratis et Socraticorum Reliquiae, Nápoles, 1990, I, pp. 405-406). Sobre Alexino en general véanse las buenas introducciones de K. Döring, «Alexinos aus Elis», en H. Flashar (ed.), Grundriss der Geschichte der Philosophie. Die Philosophie der Antike, 2/1, Sophistik - Sokrates - Sokratik usw., Basilea, 1998, pp. 218-221, y R. Muller, art. Alexinos, en R. Goulet (ed.), Dictionnaire des Philosophes Antiques 1, París, 1989, pp. 149-151.

10 La cita de Hermarco ha encontrado cabida entre los fragmentos del epicúreo primero en K. Krohn, Der Epikureer Hermarchos, Berlín, 1921, fr. 41, y más tarde en Ermarco. Frammenti, edizione, traduzione e commento a cura di F. Longo Auricchio (La scuola di Epicuro, 6), Nápoles, 1988, fr. 36, pp. 74-75 (texto), 100-101 (traducción) y 151-157 (comentario). 
por el habitual estilo correoso de Filodemo y, sobre todo, por el mal estado del papiro en la parte central de la cita ${ }^{11}$.

No obstante, Hans von Arnim hizo una reconstrucción muy lúcida del hilo de la argumentación, y expresó su convicción de haber aclarado la estructura gramatical e intelectual del pasaje ${ }^{12}$. Quien esto escribe así lo cree, pero no ve que esta convicción haya encontrado reflejo en la crítica posterior, y entiende que esto ha sido en detrimento y menoscabo de la buena comprensión del texto de Filodemo. Es cierto que von Arnim no tuvo al parecer ocasión de consultar el papiro, lo que en principio llevaría a preferir los trabajos que se han hecho a partir de un estudio directo del soporte original. Pero es innegable que la reconstrucción de un texto lagunoso de este género exige tener una concepción clara de la estructura general y del compás de la argumentación: muchas veces va a ser esta concepción global la que ayude a establecer una u otra lectura controvertida. Y esta concepción global no siempre es fruto del atinado restablecimiento del texto mutilado, sino de la correcta interpretación de lo que se lee sin dificultad ${ }^{13}$.

11 El texto se puede leer en Philodemi volumina rhetorica, ed. S. Sudhaus, I, Leipzig, 1892, pp. 78-85; S. Sudhaus, «Alexinos» (cit. en n. 9), pp. 153-154 (sólo en parte); H. von Arnim, «Ein Bruchstück des Alexinos» (cit. en n. 9), pp. 67-69 (sólo en parte); Philodemi volumina rhetorica, ed. S. Sudhaus, Supplementum, Leipzig, 1895, pp. 39-42; K. Krohn, Der Epikureer Hermarchos (cit. en n. 10), fr. 41; K. Döring, Die Megariker (cit. en n. 9), fr. 88, pp. 25-26 (sólo en parte); F. Longo Auricchio, «I filosofi megarici nella «Retorica» di Filodemo», Cronache Ercolanesi 5, 1975, pp. 77-78; F. Longo Auricchio, Philodemi De rhetorica libri primus et secundus (Ricerche sui Papiri Ercolanesi, III), Nápoles, 1977, pp. 135-145; el texto de Longo Auricchio de 1975 se reproduce en G. Giannantoni, Socraticorum reliquiae I (cit. en n. 9), pp. 65-66 (= Socratis et Socraticorum rel. I, pp. 405-406); el de 1977 en F. Longo Auricchio, «Testimonianze della Retorica di Filodemo sulla concezione della oratoria nei primi maestri epicurei», Cronache Ercolanesi 15, 1985, p. 40, y en Ermarco. Frammenti, a cura di F. Longo Auricchio (cit. en n. 10), pp. 74-75. Aquí se utiliza como texto de referencia el de Longo Auricchio de 1977.

12 H. von Arnim, «Ein Bruchstück des Alexinos» (cit. en n. 9), esp. p. 69: «ich glaube ... durch meinen Versuch wenigstens den grammatischen und gedanklichen Zusammenhang der ganzen Stelle klar gelegt zu haben».

13 Las traducciones que se han dado del texto indican más de una vez que algunas frases articulatorias de Filodemo no se han comprendido bien, y esto afecta a la comprensión global de la estructura. Se dan traducciones completas o parciales del pasaje en K. Döring, Die Megariker (cit. en n. 9), pp. 118-119; F. Longo Auricchio, «I filosofi megarici» (cit. en n. 11), p. 79; F. Longo Auricchio, Philodemi De rhetorica (cit. en n. 11), pp. 135-145, reproducida en F. Longo Auricchio, «Testimonianze» (cit. en n. 11), pp. 40-41, y en Ermarco. Framenti (cit. en n. 10), p. 100-101; L. Montoneri, I Megarici: Studio storico-critico e traduzione delle tes- 
Aquí se vuelve a retomar la orientación apuntada por von Arnim. El propósito es aclarar la estructura general, no proponer un nuevo texto (salvo en las contadas ocasiones donde esto se considera indispensable). Se propone, así pues, una base sobre la que posteriormente pueda profundizar quien tenga acceso directo al papiro.

\section{La estructura}

En la cita de Hermarco se distinguen cuatro miembros bien articulados:

\section{Primer miembro:}

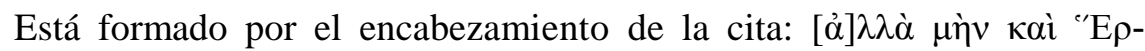

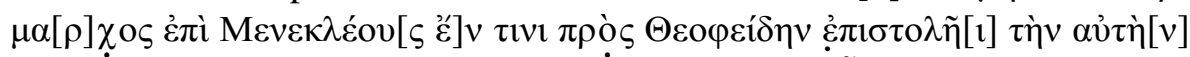

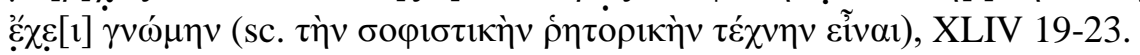

\section{Segundo miembro:}

El punto de partida de la discusión de Hermarco es la postura de Alexino, que Filodemo presenta haciendo una referencia global al título, al contenido de la obra y a unos argumentos concretos del megárico en forma de

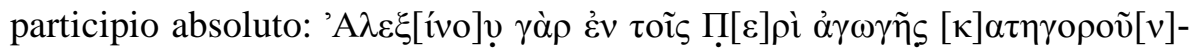

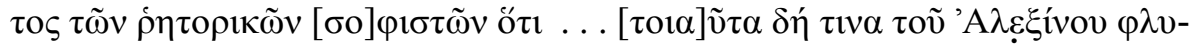

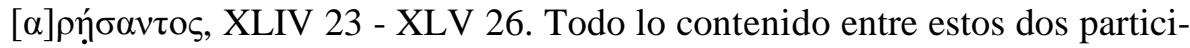
pios forma una unidad y se refiere exclusivamente a los argumentos y opiniones sostenidos por Alexino en su tratado Sobre la Instrucción. La re-

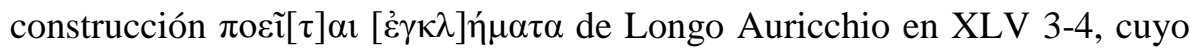
sujeto gramatical debe ser Hermarco, y que sólo puede ser Alexino si se admite un abrupto hipérbato, quiebra esta estructura y da lugar a un texto inconexo ${ }^{14}$. La razón de esta reconstrucción está en que se hace un falso corte

timonianze antiche (Symbolon, 2), Catania, 1984, pp. 270-272; y Les mégariques. Fragments et témoignages, traduits et commentés par R. Muller (Histoire des doctrines de l'Antiquité Classique, 9), París, 1985, pp. 35-36.

14 Longo Auricchio traduce en 1977: «Infatti poiché Alessino nei libri Dell'educazione accusa i retori sofisti perché compiono molte ricerche inutili - tra queste è la loro attività su-

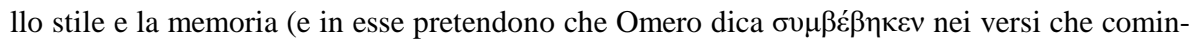

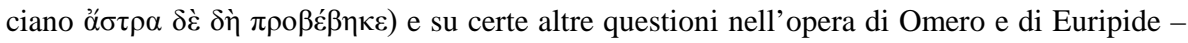
(Ermarco) muove critiche nel ricapitulare quanto è stato detto e nel concludere. Facendo poi essi etc.». Compárese la traducción en F. Longo Auricchio, «I filosofi megarici» (cit. en n. 11), p. 79, y véase allí mismo la nota 12, y los comentarios en F. Longo Auricchio, «Testimonianze» (cit. en n. 11), p. 54. La erudita italiana invoca la presencia de la $\pi \alpha \rho \alpha ́ \gamma \rho \alpha \varphi \circ \varsigma$ como 
sintáctico: Longo Auricchio entiende que tanto la palabra amputada ] $\mu \alpha \tau \alpha$

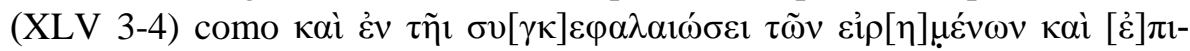
форо̃ (XLV 4-6) pertenecen a una misma unidad sintáctica. Pero, en realidad, la palabra amputada ] $\mu \alpha \tau \alpha$ se liga sintácticamente a la oración ante-

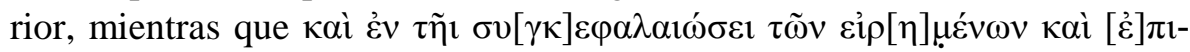

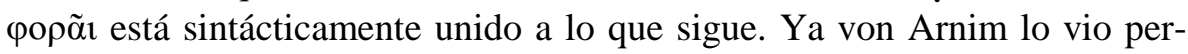
fectamente así ${ }^{15}$.

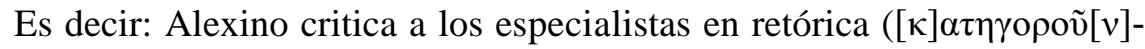

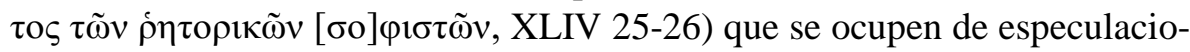

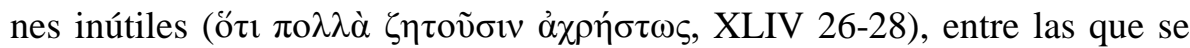

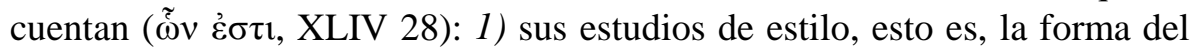

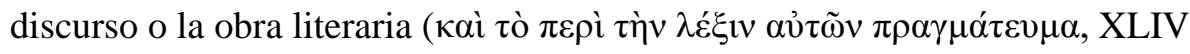

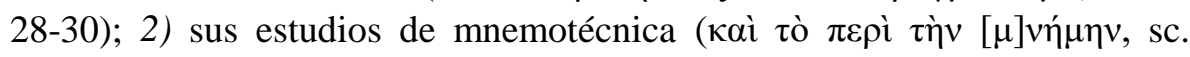

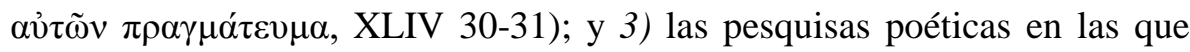

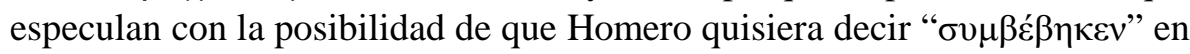

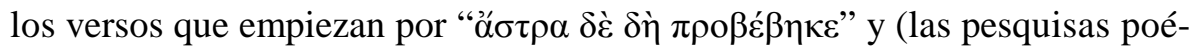
ticas) sobre algunos otros (versos) tanto de Homero como de Eurípides ( $\kappa \alpha i$

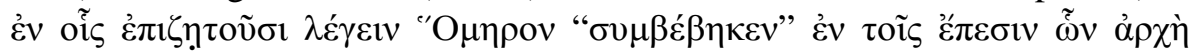

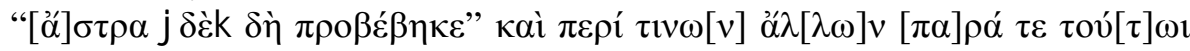

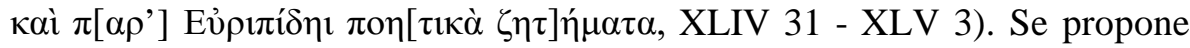

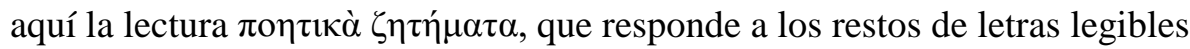

prueba de que hay un cambio de sujeto. Aquí hay que negar la mayor: no siempre es evidente qué pretende indicar la $\pi \alpha \rho \alpha ́ \gamma \rho \alpha \varphi \varsigma$ (cf. XLVII 32, donde no hay corte sintáctico alguno). L. Montoneri, I Megarici (cit. en n. 13), p. 279 y n. 22, sigue a Longo Auricchio. Sudhaus editó

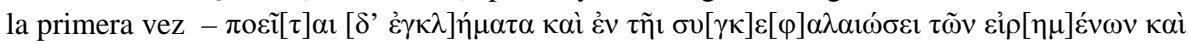

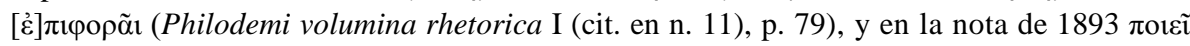

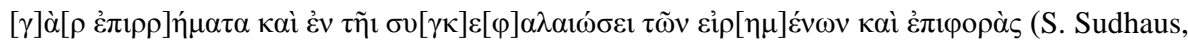
«Alexinos» (cit. en n. 9), p. 153); pero en el Supplementum de 1895, donde da su última palabra sobre el texto, se aproxima más a las propuestas de von Arnim que se indican en la nota siguiente: v. S. Sudhaus, Philodemi volumina rhetorica, Suppl. (cit. en n. 11), p. 40.

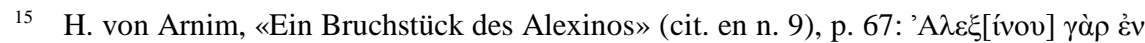

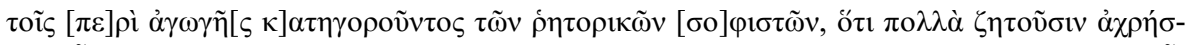

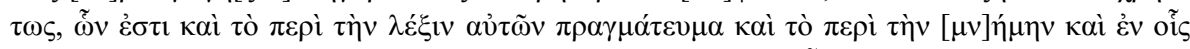

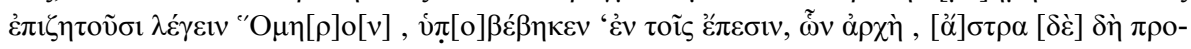

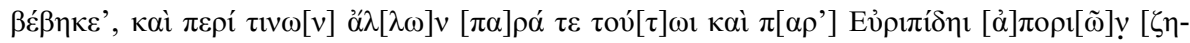

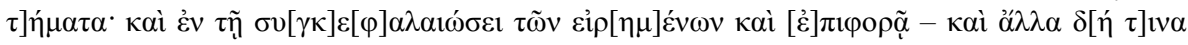

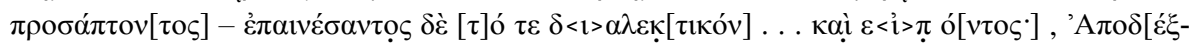
] $\alpha \tau$ o $\delta$ ' óv $[\tau \iota \zeta] \alpha \jmath ่ \tau \tilde{\omega} \nu \kappa \tau \lambda$. Cf. allí mismo la p. 71. Von Arnim entiende, evidentemente,

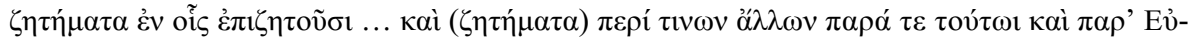

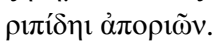




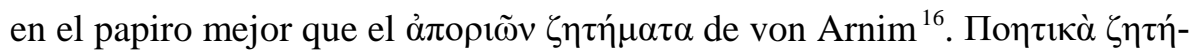
$\mu \alpha \tau \alpha$ es el antecedente de $\dot{\varepsilon} v$ oí $\dot{\varepsilon}^{\pi} \iota \zeta \eta \tau o \tilde{\sigma} \sigma \mathrm{l}$ la estructura lógica de la frase

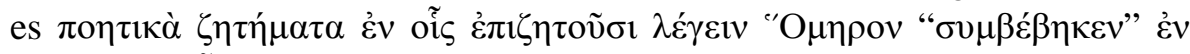

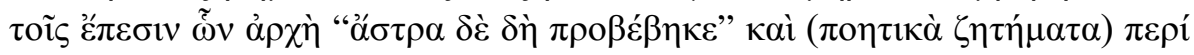

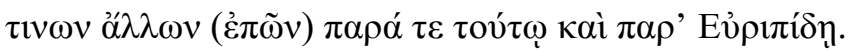

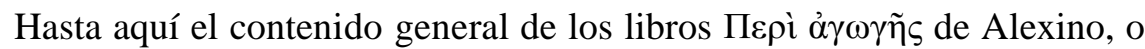
bien el contenido general de la parte que provocaba la crítica de Hermarco. Pero además, en una recapitulación de lo dicho y comentario final ${ }^{17}$, Alexino añadía algo que es lo que a Filodemo le interesa destacar, pues es lo que concretamente trae a colación la crítica de Hermarco: $\kappa \alpha \grave{~} \dot{\varepsilon} v \tau \tilde{\eta} \iota \sigma v[\gamma \kappa] \varepsilon \varphi \alpha-$

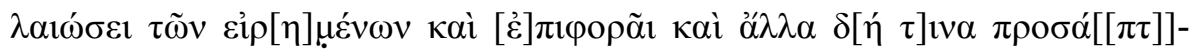
$\pi \tau \mathrm{ov}\left[\tau \mathrm{\tau} \varsigma^{18}\right]$, XLV 4-8. A partir de aquí se hace más difícil seguir el curso de la cita. Sigue a $\pi \rho \circ \sigma \alpha ́ \pi \tau o v \tau o \varsigma$ otro participio que todo hace prever en genitivo, pero que en el papiro, según la lectura de Longo Auricchio, aparece en nominativo plural masculino: غ̇ं $\alpha \mathbf{v \varepsilon ́ \sigma \alpha \nu \tau \varepsilon \varsigma , ~ X L V ~ 8 - 9 . ~ E s ~ d i f i ́ c i l ~ h a c e r ~ c a s a r ~}$

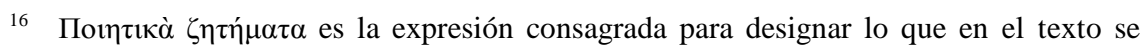

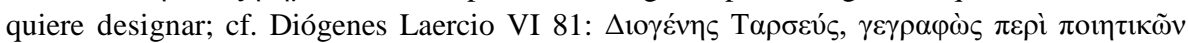

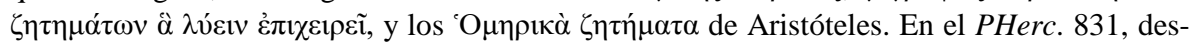
de R. Philippson, «Papyrus Herculanensis 831», AJPh 64, 1943, pp. 148-162, considerado

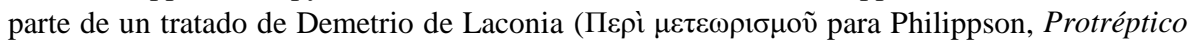

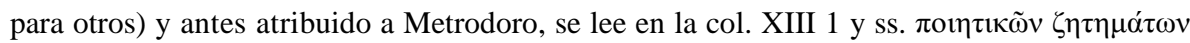

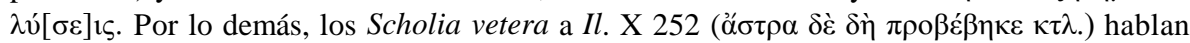

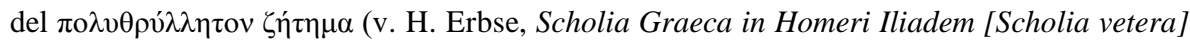
III, Berlín, 1974, p. 48), y las Quaestiones Homericae de Porfirio empiezan el comentario a

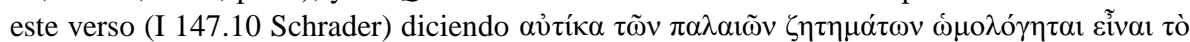

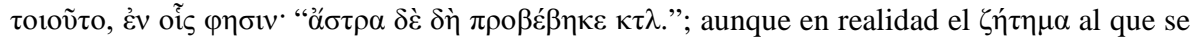
alude en el texto es el de los llamados Scholia Didymi, que se pueden leer en Scholia Graeca in Homeri Iliadem, ed. G. Dindorfius, III, Oxford, 1877, pp. 438-439. También en los Escolios a Eurípides hay alusiones a célebres $\zeta \eta \tau \eta ́ \mu \alpha \tau \alpha$; cf. por ejemplo los escolios al verso 169

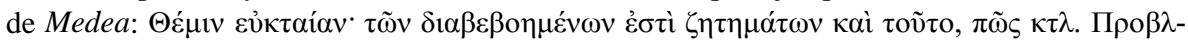

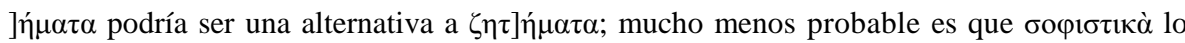

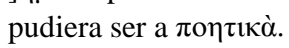

17 Ya Sudhaus daba en el Supplementum (cit. en n. 11), p. 39 n. 5, la traducción correcta

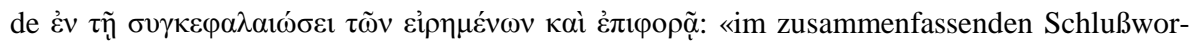
te». Cf. F. Longo Auricchio, «Testimonianze» (cit. en n. 11), pp. 54-55, y en Ermarco. Fram-

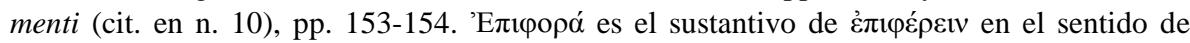
"añadir", "añadir por último", de uso frecuente.

18 F. Longo Auricchio, Philodemi De rhetorica (cit. en n. 11), p. 135, y ya en «I filosofi

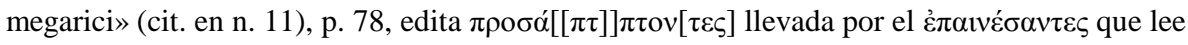
a continuación. 
el nominativo con la estructura que se ha reconstruido hasta ahora; la única

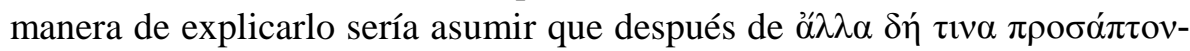

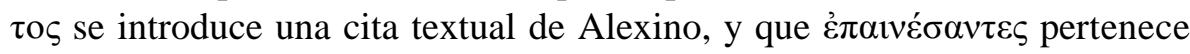
ya a la cita. Por su parte, von Arnim y Sudhaus (en el Supplementum) re-

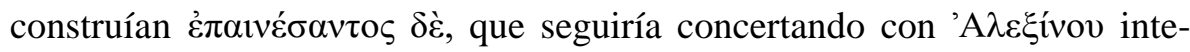
grado naturalmente en la estructura lógica del pasaje, y que sería la perfecta

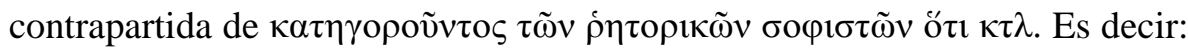
Alexino criticaba ciertas cosas a los profesionales de la retórica, pero les elogiaba otras ${ }^{19}$.

Es éste el punto más complicado de toda la estructura, pero una cosa está clara: contiene las frases o ideas de Alexino que Hermarco critica a continuación. Estas frases o ideas son $\pi \varepsilon \rho \grave{~} \chi \rho \eta \sigma i ́ \mu \omega v[\gamma \varepsilon] \pi \lambda \varepsilon i ́ \sigma \tau \omega v$ ’̌́ $\xi \omega \theta \varepsilon[v] \dot{\varepsilon} \pi t-$

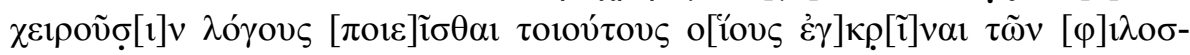

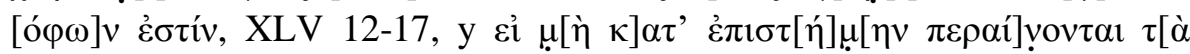

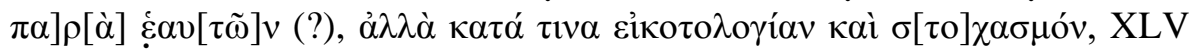
$18-22^{20}$.

Puesto que hay verbos en forma personal, o bien estamos ante una cita textual, o bien ante la completiva de un verbo de lengua. Si no se localiza este verbo de lengua con su indispensable conjunción completiva, es preferible suponer que son palabras del propio Alexino y el problema consiste entonces en delimitar la extensión de la cita textual. La sensación inmediata es que esta cita empieza con $\alpha \dot{\pi} \tau \delta \delta \dot{\varepsilon} \xi \alpha \iota \tau$ en XLV 11, como ya vieron von Arnim y Sudhaus (en el Supplementum). Se necesita entonces reconstruir un verbo introductorio en participio (genitivo) en la línea anterior, cuyo estado

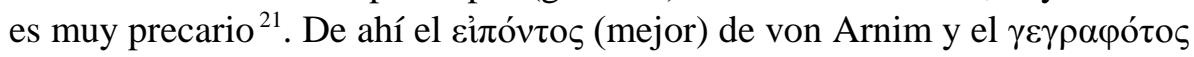

19 El texto de von Arnim se lee más arriba, en n. 15. En el Supplementum (cit. en n. 11),

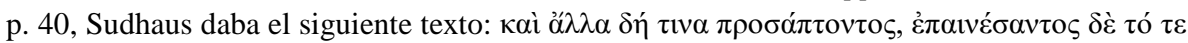

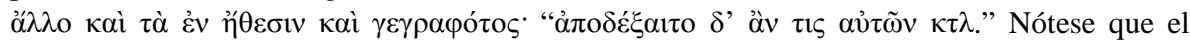

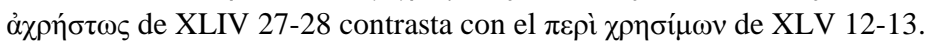

20 Véase más abajo, pp. 258-259.

21 Sobre la dificultad de reconstruir las líneas 7-10 y el carácter precario de los textos propuestos véase F. Longo Auricchio, «Testimonianze» (cit. en n. 11), p. 55, y Ermarco. Frammenti (cit. en n. 10), p. 154. La línea 10, en concreto, se resiste a una reconstrucción medianamente pasable: ANOIO . . . .EKATEIO . , apógrafo napolitano; ENHE $\Sigma$. . . $\Sigma$ KATE-

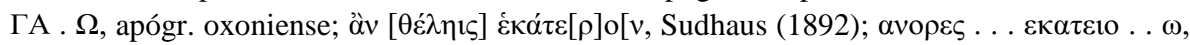

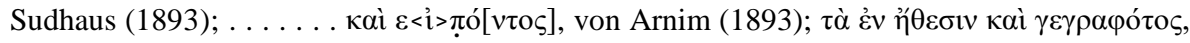
Sudhaus (1895); . NOIs . . EKATEP[. . , Sudhaus (Philodemi volumina rhetorica II, Leip-

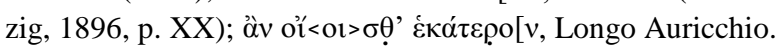


de Sudhaus ${ }^{22}$. Si un examen del papiro hace descartar esta posibilidad, que es la más sugerente, entonces habría que asumir que la cita textual se intro-

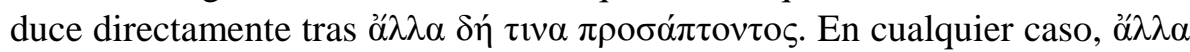
$\delta \eta ́ ~ \tau \imath v \alpha$ ( $\delta \eta ்: ~ ' a ~ l o ~ q u e ~ v a m o s ') ~ t i e n e ~ s u ~ p e r f e c t a ~ c o r r e s p o n d e n c i a ~ e n ~ e l ~ \tau o r \alpha \tilde{-}$ $\tau \alpha \delta$ j́ $\tau ı v \alpha$ de XLV 24-25.

\section{Tercer miembro:}

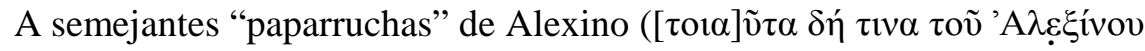
$\varphi \lambda v[\alpha] \rho \underline{\sigma} \sigma \alpha v \tau o \zeta$, XLV 24-26) opone Filodemo la discusión de Hermarco,

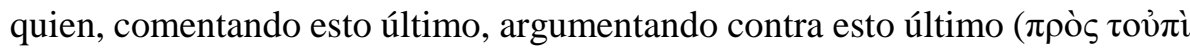

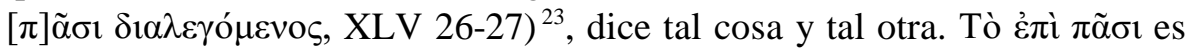
evidentemente "lo último" ${ }^{24}$, y, en efecto, en la discusión de Hermarco se distinguen las dos frases que cierran el miembro anterior y las pertinentes observaciones del epicúreo (XLV 27-XLVIII 31 y XLVIII 31- XLIX 19, respectivamente):

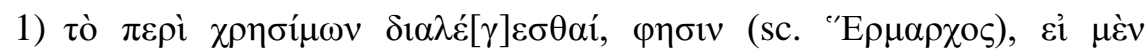
$\tau \alpha \hat{}[\tau \grave{o}] v \delta \varepsilon \tilde{\imath} \lambda \alpha \beta \varepsilon \tilde{v} v \kappa \tau \lambda$., XLV 27-XLVIII 31, que comenta el $\pi \varepsilon \rho \grave{~}$ $\chi \rho \eta \sigma i ́ \mu \omega v[\gamma \varepsilon] \pi \lambda \varepsilon i ́ \sigma \tau \omega v \kappa \tau \lambda$., XLV 12-17, de Alexino. La discusión se centra en el sentido de $\chi \rho \eta \sigma i ́ \mu \omega v$, y se distinguen al menos tres supuestos, es decir, tres acepciones en las que Hermarco entiende que se

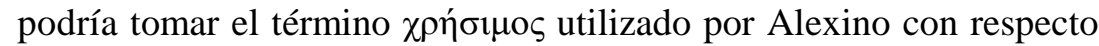

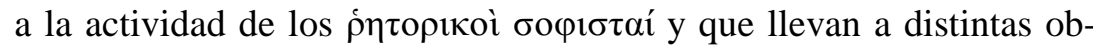
servaciones ${ }^{25}$ :

a) Si Alexino utiliza $\chi \rho \eta ́ \sigma \mu o \varsigma$ en un sentido crematístico (materialmente provechoso, apropiado para ganar dinero), Hermarco lo considera un dis-

22 Véanse los textos en n. 15 y 19, respectivamente.

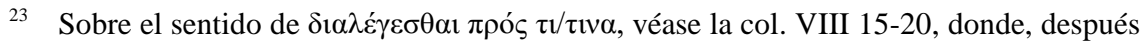
de haber citado y rebatido una por una distintas afirmaciones en contra del carácter de $\tau \varepsilon ́ \chi v \eta$

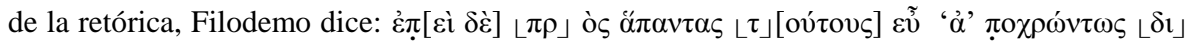

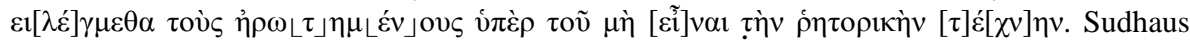

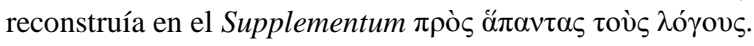

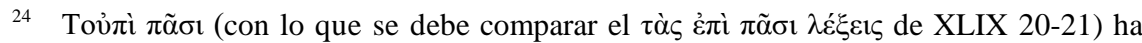
dado incomprensiblemente muchos problemas a los traductores: «indem er die Äusserungen insgesamt angreift», «discutendo contro ciò che è comune a ogni cosa», «attacando tutte quelle affermazioni», «Hermarque s'oppose de façon globale», «mettendo in discussione ogni punto».

25 Véase ya H. von Arnim, «Ein Bruchstück des Alexinos» (cit. en n. 9), pp. 68-69, y S. Sudhaus, Philodemi volumina rhetorica, Supplementum (cit. en not. 11), pp. 39-40 n. 5. 


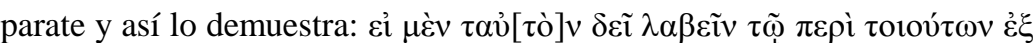

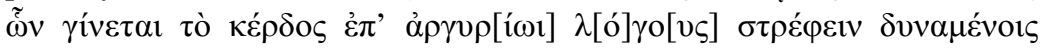
$\kappa \tau \lambda .$, XLVI 29 - XVLIV 5.

b) En el segundo supuesto falta la prótasis, que ha desaparecido en buena medida con la laguna de XLVI 7-25. Pero puesto que en el comentario se habla de jueces y causas, cabe suponer que Hermarco considerase la posi-

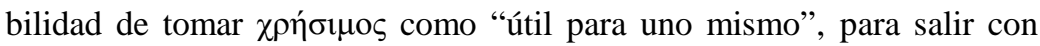

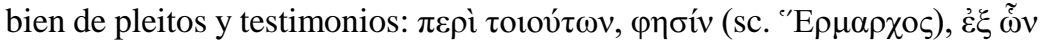
бvví $\tau \alpha \tau \alpha[1] \kappa \tau \lambda$., XLVI 6-XLVII 20. Nos movemos en la esfera de la actividad forense y de la aplicación de la formación retórica en este campo.

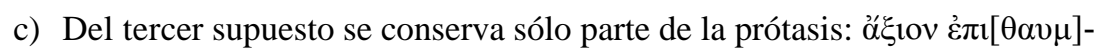

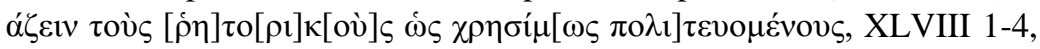
y el pertinente comentario de Hermarco, XLVIII 5-31. Parece que por últi-

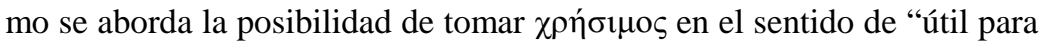
los demás, útil para la vida pública". Se pasa, así pues, a la esfera de la actividad política y a la aplicación de la formación retórica en este dominio.

Hay que reparar en que es precisamente en el comentario del sentido que $\chi \rho \eta ́ \sigma u \mu \varsigma \varsigma$ pueda tener en Alexino donde Hermarco entra de lleno en el debate sobre la utilidad de la retórica en sus aplicaciones prácticas de la actividad forense y política, y en que es aquí donde

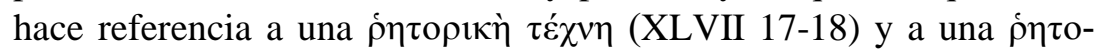

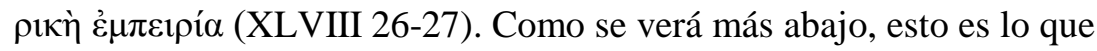
verdaderamente interesa a Filodemo y lo que la cita de Hermarco aporta a su demostración ${ }^{26}$.

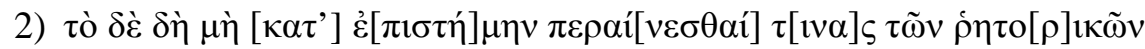

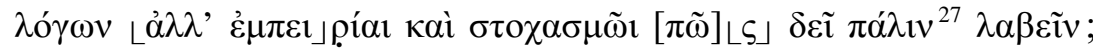
o[v่] $\gamma \grave{\alpha} \rho \kappa \tau \lambda$., XLVIII 31 - XLIX 19, que comenta brevemente el $\varepsilon \hat{i}$ $\mu[\grave{\eta} \kappa] \alpha \tau^{\prime} \dot{\varepsilon} \pi \iota \tau \tau[\dot{\eta}] \mu[\eta v \kappa \tau \lambda .$, XLV 18-22, de Alexino.

\section{Cuarto miembro:}

Finalmente, Filodemo añade una coletilla para justificar la inclusión en

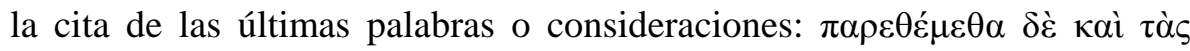

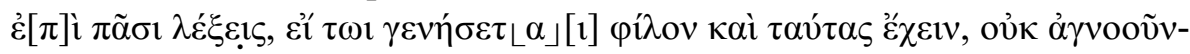

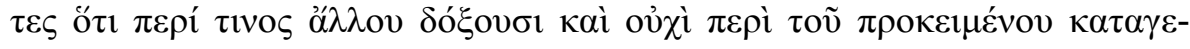

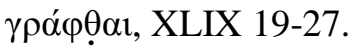

26 Véase más abajo, pp. 259-262.

27 Пád $v$ 'a su vez' marca el tránsito al comentario de la segunda frase o idea de Alexino. 
Se suele admitir un tanto precipitadamente que con esta última frase $\mathrm{Fi}$ lodemo pretende disfrazar la irrelevancia de la cita de Hermarco para la demostración que está llevando a cabo, con lo que el filósofo de Gádara queda en una posición francamente ridícula ${ }^{28}$. Pero la cita de Hermarco no es en absoluto irrelevante para la demostración de Filodemo, ni, por supuesto,

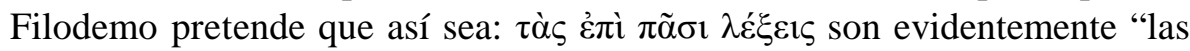
últimas palabras", "el final de la cita" ${ }^{29}$, y se refiere o bien a la alusión a Eubúlides, o bien, y con toda probabilidad, a todo el comentario de Hermar-

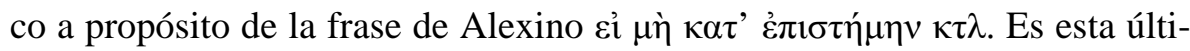
ma parte la que "puede parecer" no estar relacionada con el propósito de la cita, y es esto lo que provoca la justificación de Filodemo.

Que la esencia de la cita de Hermarco se halla en el comentario a la prime-

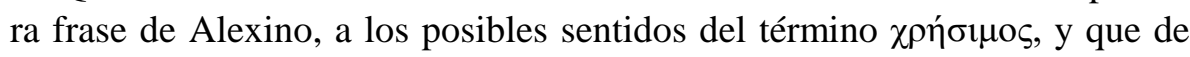
ahí debe deducirse según Filodemo la postura de Hermarco respecto a la con-

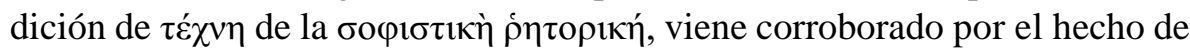
que Filodemo cita esta misma carta de Hermarco en otro pasaje de su Пвpì

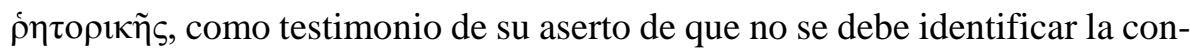

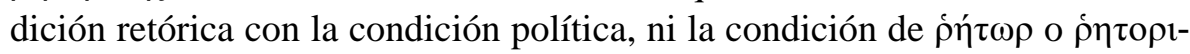
кó con la de político ${ }^{30}$. Es ésta, en realidad, la esencia de la polémica que

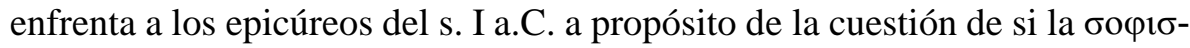

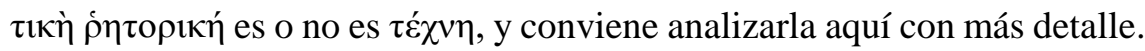

28 Véase S. Sudhaus, Philodemi volumina rhetorica I (cit. en n. 11), p. XXXII; S. Sudhaus, Philodemi volumina rhetorica, Supplementum (cit. en n. 11), p. 42; F. Longo Auricchio, «I filosofi megarici» (cit. en n. 11), p. 80, también en «Testimonianze» (cit. en n. 11), p. 54, y en Ermarco. Frammenti (cit. en n. 10), pp. 152-153; D. Sedley, «Philosophical Allegian-

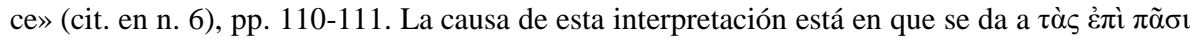
$\lambda \dot{\varepsilon} \xi \varepsilon 1 \zeta$ un significado que la expresión no puede tener: «queste citazioni integralmente testuali», «I have cited the full context».

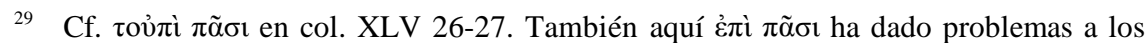
traductores; véase la nota anterior. $\Lambda \varepsilon^{\prime} \xi$ is es el término consagrado para "palabra textual", "ci-

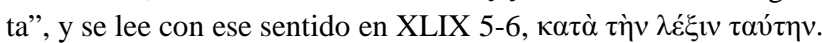

30 Filodemo, Rhet. Lib. inc. (PHerc. 1506), col. XLIV 17-33 (en S. Sudhaus, Philodemi

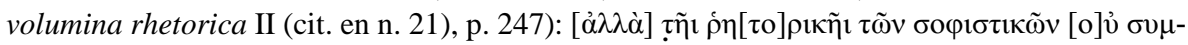

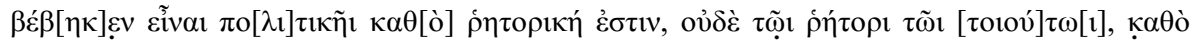

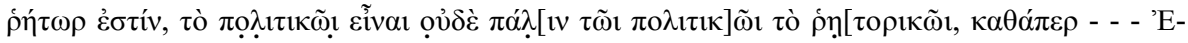

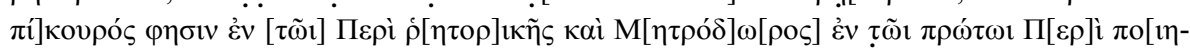

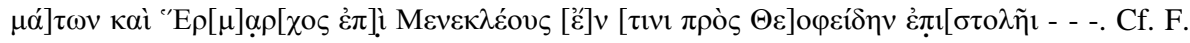
Longo Auricchio, «Testimonianze» (cit. en n. 11), p. 34, y Ermarco. Frammenti (cit. en n. 10), p. 76 (fr. 39). 
Las diatribas de los $\kappa \alpha \theta \eta \gamma \varepsilon \mu$ óvєৎ de la escuela epicúrea acerca del valor de la retórica versaban sobre la cuestión de si la teoría y práctica de la elaboración del discurso en sentido lato, que es una realidad incuestionada e incuestionable, con su práctica y su instrucción propias, trasciende a la esfera de la actividad política y, subsidiariamente, forense, es decir, si la formación retórica habilita para la vida pública y por tanto hay una formación específica para la vida pública y un arte de ejercerla. Los $\kappa \alpha \theta \eta \gamma \varepsilon \mu o ́ v \varepsilon \varsigma ~ l o$ negaban. Para parte de los epicúreos del s. I a.C. la discusión se ha desplazado y focalizado en la condición de $\tau \dot{\varepsilon} \chi v \eta$ - en sentido estricto: disciplina metódica - de la propia teoría y práctica del discurso, y se pretende encontrar en los textos canónicos de la secta posicionamientos respecto a esta cuestión. Para los epicúreos de Rodas y Cos, al parecer, la negación de que haya una formación específica, y por tanto una "ciencia" específica, para la vida pública arrastra consigo la negación de que la formación y la práctica retóricas, que están en la base de la formación para la vida pública, sean una "ciencia" específica. Para Filodemo, en cambio, se debe deslindar la condición de lo político de la de lo retórico: lo que los $\kappa \alpha \theta \eta \gamma \varepsilon \mu o ́ v \varepsilon \varsigma$ niegan es el carácter de "ciencia" de lo primero, pero ello no arrastra consigo la condena de la retórica a no ser $\tau \dot{\varepsilon} \chi v \eta$. Al contrario, el mero hecho de que los maestros

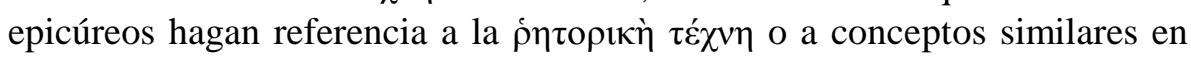
sus disputas sobre la inexistencia de una "ciencia" política demuestra la existencia de una "ciencia" retórica.

Además, Filodemo sostiene, en abierta polémica con sus adversarios, que

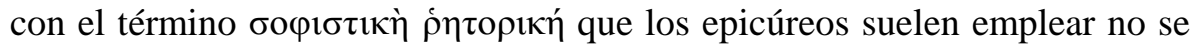
está haciendo alusión a lo que tradicionalmente se llama la oratoria epidíctica o panegírica - ya que ése es, al parecer, el uso corriente de la expresión -, sino a lo que la retórica tiene de teoría y práctica concretas al margen de sus aplicaciones en el foro, en la tribuna o en el estrado del panegirista; es decir, a lo que tiene de $\tau \dot{\varepsilon} \chi v \eta^{31}$.

Por tanto, como demuestran los comentarios sobre Epicuro que preceden a la cita de Hermarco y la cita de Metrodoro que la sigue, el mero hecho de

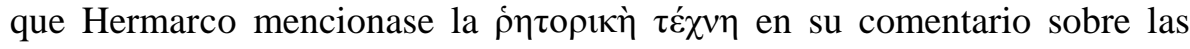

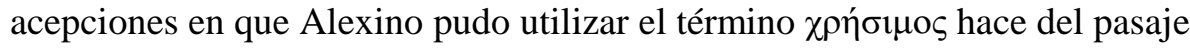
una prueba de lo que Filodemo se propone demostrar ${ }^{32}$. Y, por ende, la cita

31 Es éste un punto muy importante que se suele perder de vista: v. nota final.

32 En el caso de Epicuro (XLIV 2-19), Filodemo no hace sino constatar que en su obra

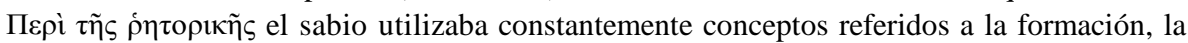


de Hermarco no es en absoluto irrelevante - no más ni menos de lo que po-

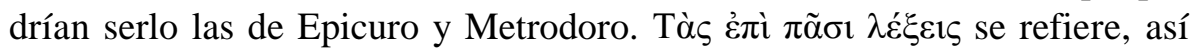
pues, al final de la cita.

\section{Alexino-Hermarco-Filodemo: recapitulación}

Por último, cabe resumir brevemente la información que la cita de Filo-

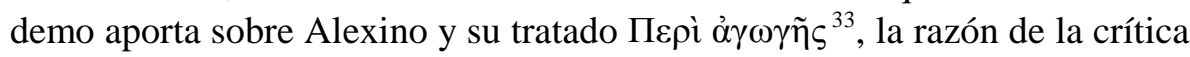
de Hermarco y el motivo de que Filodemo cite esta crítica.

En la parte mejor conservada del texto, la introductoria, se lee con facilidad que Alexino recrimina a los profesionales de la retórica (oi

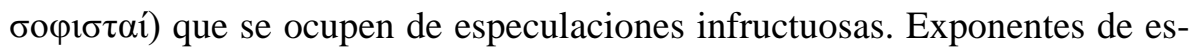

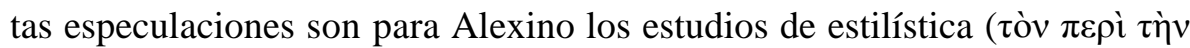

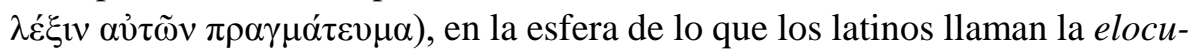
tio. Esta actividad se corresponde con el tipo de tratado bien conocido titula-

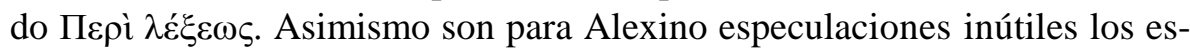
tudios de mnemotécnica (

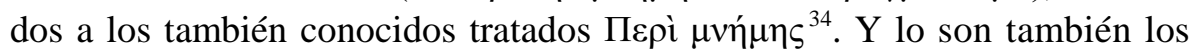

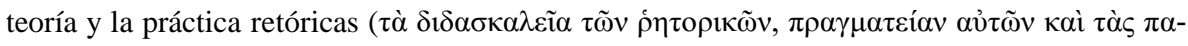

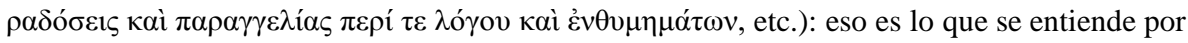

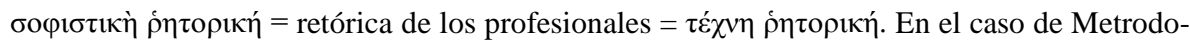

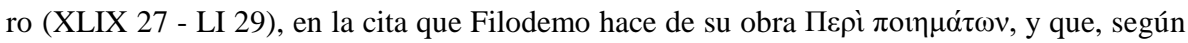

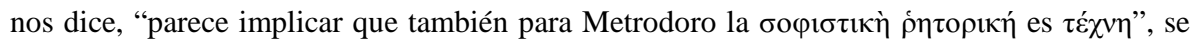
hace mención explícita de $\dot{\eta} \tau \tilde{\omega} v \rho \dot{\eta} \tau$ o $\iota \kappa \tilde{o} \nu \tau \dot{\varepsilon} \chi v \eta$.

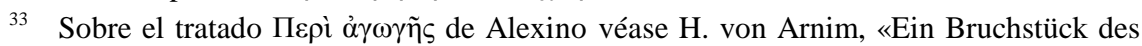
Alexinos» (cit. en n. 9), pp. 70-72; Id., «Sophistik, Rhetorik, Philosophie in ihrem Kampf um die Jugendbildung», introducción a Leben und Werke des Dio von Prusa, Berlín, 1898, p. 21; K. Döring, Die Megariker (cit. en n. 9), pp. 119-120; L. Montoneri, I Megarici (cit. en n. 13), pp. 118-121; R. Muller, Les mégariques (cit. en n. 13), pp. 123-126; Id., Introduction à la pensée des mégariques (Bibliothèque d'Histoire de la Philosophie, Cahiers de Philosophie Ancienne, 6), París - Bruselas, 1988, pp. 116-117; K. Döring, «Alexinos aus Elis» (cit. en n. 9), pp. 219-220. Si se aplica aquí lo observado por D. Delattre, «Les mentions des titres d'oeuvres dans les livres de Philodème», Cronache Ercolanesi 26, 1996, p. 118, el decir Filo-

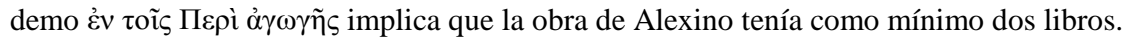

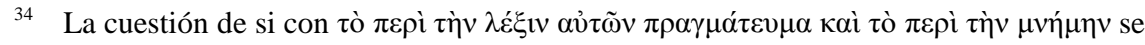
designan tratados escritos o meros ejercicios orales, planteada por G.A. Kennedy, The Art of Persuasion in Greece, Princeton, 1963, p. 318, no parece muy relevante. En cualquier caso, H. Blum, Antike Mnemotechnik (Spudasmata, 15), Hildesheim - Nueva York, 1969, pp. 123124, creyó necesario defender que se designan tratados escritos, y su postura ha encontrado respaldo en K. Döring, Die Megariker (cit. en n. 9), p. 118 n. 2, y en F. Longo Auricchio, 
estudios de exegesis poética, particularmente los que se cifran en términos de

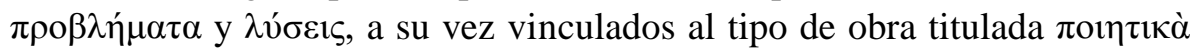
$\zeta \eta \tau \eta \dot{\mu} \mu \alpha \alpha$ o $\pi \rho \circ \beta \lambda \eta \dot{\mu} \mu \alpha \alpha$ o similar.

Mayor dificultad entraña la reconstrucción de lo que se decía en lo que

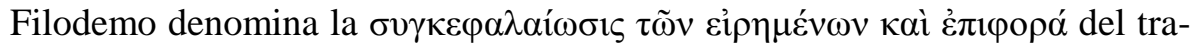
tado de Alexino, o de la parte de él que provocaba la crítica de Hermarco. La atención parece volverse aquí hacia la práctica de la retórica, a la que se reconocen ciertos aspectos de utilidad. Estos aspectos de utilidad - y se entra aquí en la esfera de intereses que según los testimonios son los propios de Alexino - parecen relacionarse con el ámbito de la argumentación y de los mecanismos de la lógica. Según Alexino, al parecer, la retórica pone en práctica estos mecanismos lógicos, pero no de una manera sistemática y científica, sino rutinaria e intuitivamente. En la medida en que esto es así, la retórica merece la aprobación de Alexino ${ }^{35}$.

Pero desde el momento en que se reconoce un aspecto de utilidad a la retórica, entra en juego la crítica de Hermarco, que no puede reconocer que en la utilidad celebrada por Alexino haya nada que trascienda a la aplicación de la retórica en la vida pública, puesto que esto entraría en contradicción con la doctrina epicúrea en la materia: si la aplicación de la formación retórica a la vida pública entraña aspectos de utilidad $(\chi \rho \eta ́ \sigma \mu \alpha)^{36}$, la retórica se

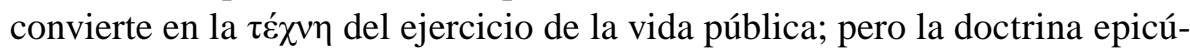
rea defiende que para tal cosa no existe una $\tau \dot{\chi} \chi v \eta$. En cuanto a Filodemo, lo que pretende demostrar con el texto de Hermarco es que a lo que aquí se niega la condición de $\tau \dot{\chi} \chi v \eta$ es a esa trascendencia de la formación retórica a la actividad pública; es decir: la formación retórica no es una formación política, no es $\tau \dot{\varepsilon} \chi v \eta$ en la esfera de su aplicación política; pero ello no implica que la formación retórica no sea en sí, en lo que tiene de sistemático y me-

«Testimonianze» (cit. en n. 11), p. 54, y en Ermarco. Frammenti (cit. en n. 10), p. 153.

35 Sobre los vínculos aparentemente establecidos por Alexino entre dialéctica y retórica véanse las interesantes consideraciones de R. Muller, Les mégariques (cit. en n. 13), pp. 123126, y Introduction à la pensée des még. (cit. en n. 33), pp. 116-117.

36 Para valorar la importancia que el sentido de $\chi \rho \eta ́ \sigma \mu о \varsigma$ tiene para Hermarco hay que

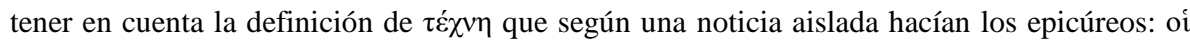

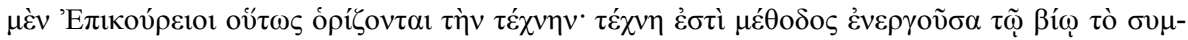
pépov (Escolios a Dionisio Tracio 649 b 25, 108.27 Hilgard = Epicuro, fr. 227b Usener). Es el concepto de "utilidad", "provecho", el que guía la argumentación de Hermarco: no puede admitir que la retórica tenga ninguna utilidad en el ámbito de la política y la vida pública porque esto la equipara a una $\tau \dot{\chi} \chi \vee \eta$ de la política y de la vida pública. 


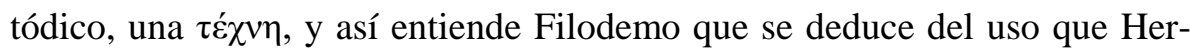

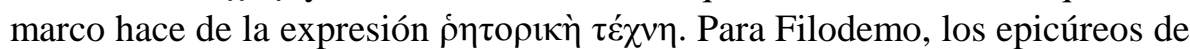
Rodas y Cos no alcanzan a comprender esta disociación entre la esfera de lo retórico y de lo político, y malinterpretan por ende la doctrina de los $\kappa \alpha \theta \eta$ -

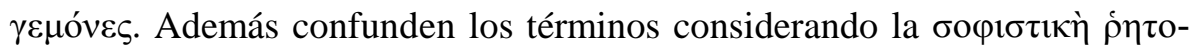
рıќ́ una parte de la retórica (equiparable, al parecer, a la oratoria panegírica por oposición a la forense y a la deliberativa): Filodemo precisa que por

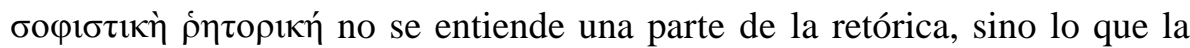
retórica tiene en sí de sistemático y metódico en su teoría y en su práctica, es decir, lo que tiene de $\tau \varepsilon \dot{\chi} \chi \nu \eta^{37}$. Ésa es la razón de que se citen los pasajes

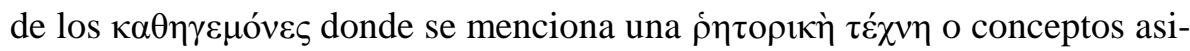
milables a éste.

37 En D. Blank, «Philodemus on the Technicity of Rhetoric», en D. Obbink (ed.), Philodemus and Poetry. Poetic Theory and Practice in Lucretius, Philodemus and Horace, Oxford, 1995, pp. 178-188 (también, en versión abreviada, en G. Giannantoni - M. Gigante (eds.), Epicureismo Greco e Romano. Atti del Congr. Intern. Napoli, 19-26 Maggio 1993, Nápoles, 1996, II, pp. 585-596), se hallarán interesantes matizaciones sobre la condición de

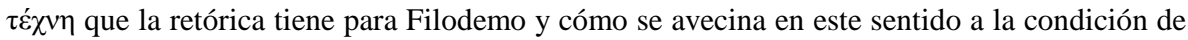
la poética. Es interesante subrayar que Filodemo considera que hay un componente metódico en la retórica de los profesionales (y por lo tanto hay $\tau \dot{\varepsilon} \chi v \eta$ ), pero limitado, como en el caso

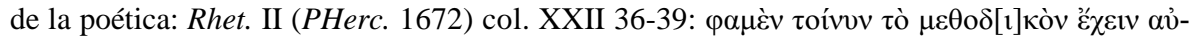

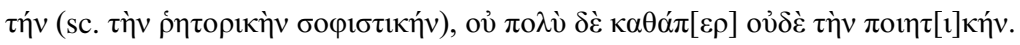


NOTA FINAL

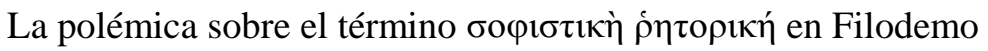

Es éste un punto muy importante que se suele perder de vista: cf. Rhet. II

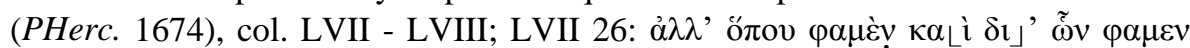

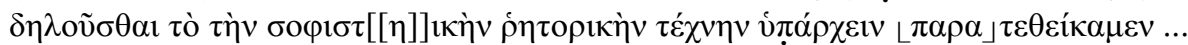

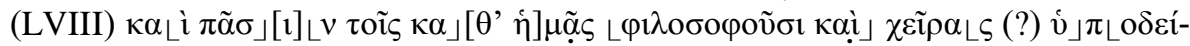

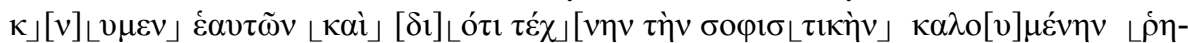

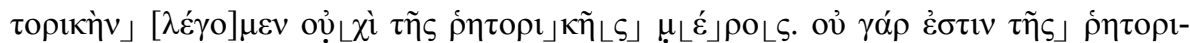

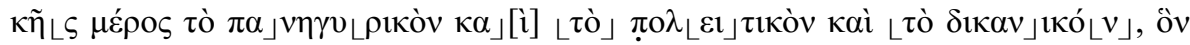

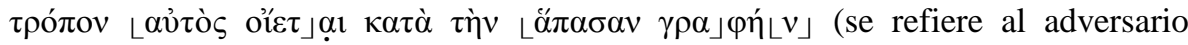

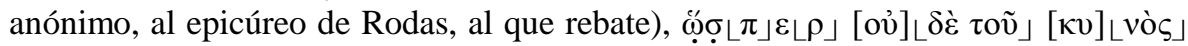

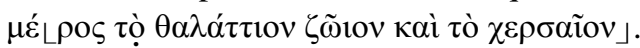

Hay que tener en cuenta que la polémica que Filodemo sostiene en el libro II del

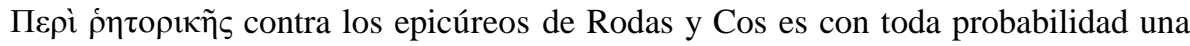
réplica. La hipótesis de S. Sudhaus, «Exkurse zu Philodem. 1. Ein litterarischer Streit in der epikureischen Schule», Philologus 54, 1895, pp. 80-85, según la cual Filodemo habría publicado un primer opúsculo identificable con el denominado

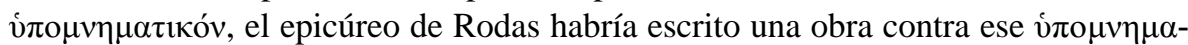

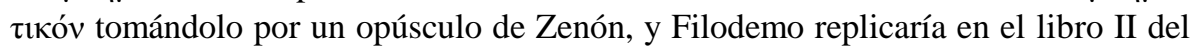

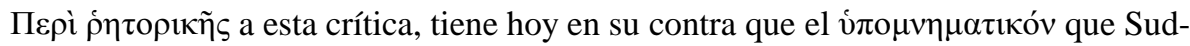

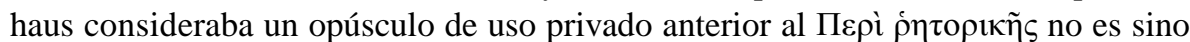
una copia de uno de los libros de esta obra: véase T. Dorandi, «Per una ricomposizione» (cit. en n. 6), pp. 65-66.

Pero al margen de que el vं que en el círculo epicúreo de Atenas, al que pertenece Filodemo, se sostenía que la

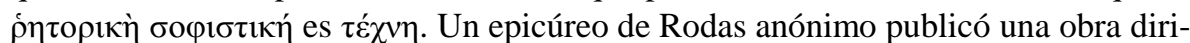
gida contra Zenón rebatiendo esta tesis sostenida por el círculo de Atenas. En ella afirmaba, según se deduce del índice del contenido reproducido por Filodemo, que en las obras de los $\kappa \alpha \theta \eta \gamma \varepsilon \mu o ́ v \varepsilon \varsigma$ no se hallaba el menor rastro de que se considerase

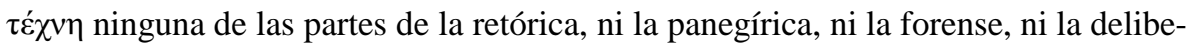

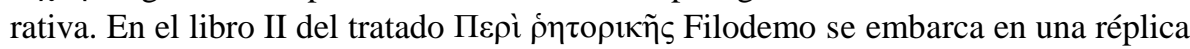
a las críticas del epicúreo de Rodas y le reprocha que haya confundido los términos:

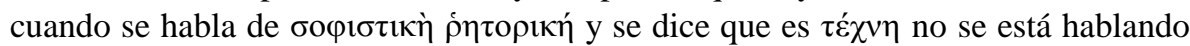

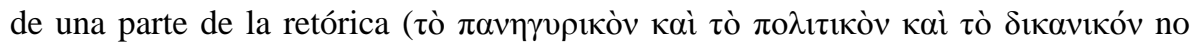
son partes de la retórica, sino aplicaciones concretas de ésta), sino de la retórica en sí, de lo que tiene de metódico y sistemático, en la elaboración del discurso y en su ejecución, aparte de sus aplicaciones concretas.

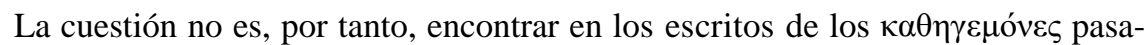

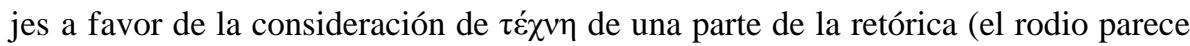
entender que la panegírica o epidíctica), sino probar que en los escritos de los 


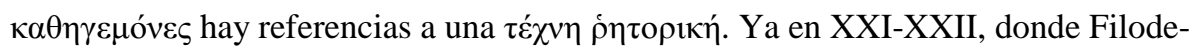

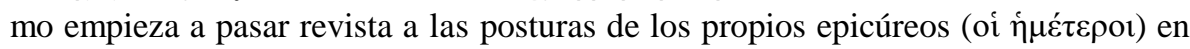

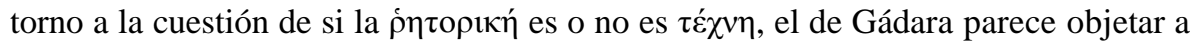
una postura que, si no es la suya, es muy parecida a la suya, precisamente el que "dé

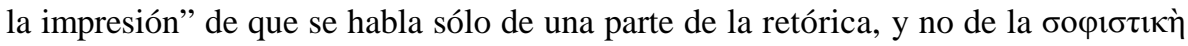

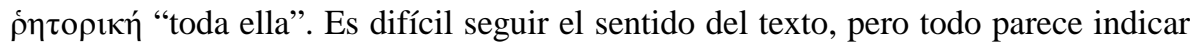
que Filodemo reprocha a una postura cercana a la suya (¿la del círculo de Atenas?) precisamente las imprecisiones terminológicas que han dado pie a la incomprensión

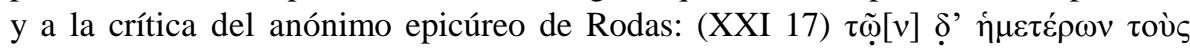

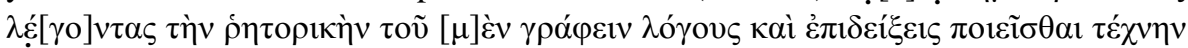

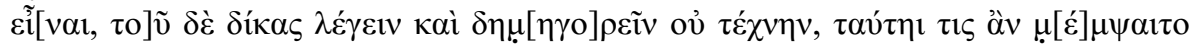

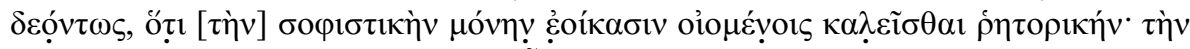

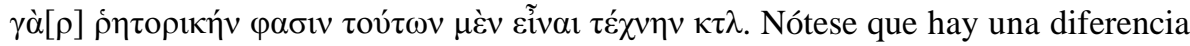

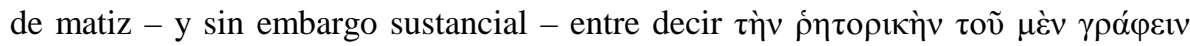

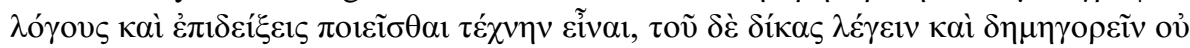

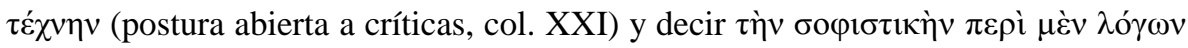

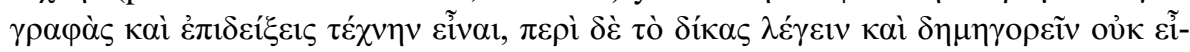
$\vee \alpha \iota \tau \dot{\varepsilon} \chi \vee \eta v$ (postura propia, col. XXXVII). 